\title{
Performance Enhancement of Reverse Osmosis (RO) Membrane Using Nanocomposite Materials
}

\author{
A.E.Kabeel ${ }^{1}$, A. Khalil ${ }^{1}$, Y.A. F. EL-Samadony ${ }^{2}$, and Maisa A. Sharaf ${ }^{3, *}$ \\ ${ }^{1}$ Mechanical Eng. Department, Faculty of Engineering, Tanta University, Tanta, Egypt \\ ${ }^{2}$ Mechanical Eng. Department, Faculty of Engineering, Beirut Arab University, Beirut, Lebanon \\ ${ }^{3}$ Mechanical Eng. Department, Faculty of Engineering, Kafrelsheikh University, KafrElsheikh, Egypt \\ * Corresponding author, E-mail address: mech.enge@yahoo.com
}

Abstract- Many attempts were made to enhance the performance of reverse osmosis (RO) membranes in the desalination process. Using ion exchange (IX) bed before RO process and modifying the structure of RO membranes are some of these attempts. Thin film nanocomposite (TFN) membrane is the novel type of RO membranes which is the best in nanofiltration applications. TFN membranes have many new advantages due to the change of their structure in comparison with traditional membranes. In this study the performance of a TFN membrane was compared with that of standard thin film composite (TFC) spiral wound water desalination RO membrane for filtration of IX produced water. The results from the filtration process showed that the flux and water permeability of TFN are 1.55 and 1.56 times that of TFC for feed water with $2050 \mathrm{ppm} \mathrm{NaCl}$ concentration with nearly unchanged level of the membrane salt rejection, which will reduce the filtrated water cost.

Keywords: TFN membrane, RO membrane, flux, performance enhancement, membrane permeability, nanocomposite materials, ion exchange

\section{INTRODUCTION}

IX process is used to enhance the performance of RO membrane by removing different ions from water in water treatments. In this study zeolite bed before RO process is used. Many authors [1-3] in their studies using IX process as a pretreatment before RO desalination process. They found that Hybrid IX-membrane process is a promising solution to prevent membrane scaling and fouling also can reduce the desalination costs. RO desalination process after IX pretreatment predicted $90 \%$ recovery and reducing the produced water cost by $75 \%$.[4].

In a research for desalination of saline sludge by Ghaly and Verma [5], they passed the wash water through a column of zeolite for salt reduction. The efficiency of sodium salt removal was $75.34 \%$ and increased to $99.79 \%$ when using two ion exchange columns.

Shokrian et al. [6] in their study to remove $\mathrm{NaCl}$ from aqueous solutions using zeolite, provided strong support for $\mathrm{NaCl}$ adsorption by zeolite and the adsorption efficiency increased with zeolite mass increasing.

Wibowo et al. [7] studied the performance of using natural zeolite for seawater desalination. The salinity reduction was $3200 \mathrm{ppm}$ and $9.14 \%$ was the efficiency of that reduction at $7.5 \mathrm{~g}$ sorbent mass.
However, the development in RO technology, it has many disadvantages, fouling is one of them. Fouling leads to flux decrease of the RO membrane which leads to increase of the operating costs. By incorporating appropriate amount of nanomaterial into polyamide layer of thin film composite membrane, TFN membrane can be produced with novel characteristics compared with the traditional TFC membrane which enhances membrane water permeability. Hegab et al. [8] investigated that the modification of TFC membrane using graphene oxide will enhance the membrane antifouling and provide less flux decline than the traditional one and achieved $97 \%$ water flux recovery ratio.

Many researchers [9-14] have reported that thin film nanocomposite RO membranes will improve the membrane performance by increasing membrane permeability, durability and chlorine resistance compared with TFC membrane. Also, inorganic nanoparticles incorporatation can increase the permeability of the polyamide membrane by providing a direct path for water transport and increasing the membrane water flux.

Jeong et al. [15] studied the effect of embedding a small quantity of zeolite into polyamide layer of TFC membrane and they found that the produced TFN membrane has smoother and more hydrophilic surface which will increase membrane water permeability with no effect on salt rejection. This performance due to the characteristics of zeolite that offer preferential flow paths for water molecules through its super-hydrophilic surface. Lau et al. [16] in their review made a comparison between three research groups using zeolite nanoparticles incorporation into polyamide layer, they found that there is a great enhancement of the water permeability with the same salt rejection but the degree of flux depending on enhancement varied with the zeolite type and loading.

Porous $\mathrm{NaA}$ nanozeolites particles were incorporated into thin polyamide layer in a novel approach to enhance RO membrane performance. A microporous structure of $\mathrm{NaA}$ with $0.42 \mathrm{~nm}$ in diameter enables water molecules $(0.27 \mathrm{~nm}$ in diameter) to pass through these micropores more easily than dense layer of polyamide [17].

Ghanbari et al. [18] used titanium dioxide $\left(\mathrm{TiO}_{2}\right)$ nanoparticles as nanofillers in the preparation of TFN membranes for forward osmosis (FO) application. The results revealed that the produced membrane has excellent anti- 
fouling features and high water permeability. In a study by Ghosh et al. [19] with various zeolite loading and size, the produced membranes are smoother, more hydrophilic and more negatively charged than normal TFC membranes prepared under identical condition and have less fouling tendency than the TFC membrane.

Durgun et al. [20] synthesized a series of polyamide TFC and TFN membranes with different nanoparticle content, $0 \mathrm{wt} \%, 0.15 \mathrm{wt} \%, 0.30 \mathrm{wt} \%$. The membranes were tested in lab for $3000 \mathrm{~h}$ and they found that at the highest zeolite loading tested in comparison with the TFC membrane, water permeability increased from $3.7 \pm 0.6 \mu \mathrm{mMPa}^{-1} \mathrm{~s}^{-1}$ to $5.3 \pm 0.5$ $\mu \mathrm{mMPa}^{-1} \mathrm{~s}^{-1}$ and solute rejection slightly increased from $97.4 \pm 0.3 \%$ to $97.9 \pm 0.1 \%$. In that study TFN membranes exhibited long term desalination stability and improved separation performance compared to TFC membranes.

In this paper, the effect of using saline water which is treated with zeolite bed as feed water for TFC and TFN reverse osmosis membranes is studied. Also, a comparison between the performance of TFC and TFN membranes in RO desalination process without IX treatment is held.

\section{EXPERIMENTAL WORK}

\section{A. Materials}

In this experiment, two types of RO membranes are used. The first is TFC-RO membrane FilmTec ${ }^{\text {TM }}$ TW30-1812-100 and the second membrane is TFN-RO membrane LG TWRO1812-100 from $\mathrm{NanoH}_{2} \mathrm{O}$, which is a TFN membrane within zeolite nanoparticles. Both of these membranes are standard spiral wound 1.8 in elements. In zeolite IX bed we used zeolite with 3-6 mm particle size and $250 \mathrm{~g}$ zeolite mass in the bed, from A\&O Company with the chemical composition in Table 1 from the Central metallurgical research and development institute (CMRDI). There are many types of zeolite but we use Clinoptilolite because it is the most abundant and low cost type.

TABLE I

CHEMICAL COMPOSITIONS FOR MAJOR ELEMENTS OF USED NATURAL ZEOLITE (CLINOPTILOLITE)

\begin{tabular}{|l|l|l|l|l|l|l|l|}
\hline \multicolumn{7}{|c|}{ Chemical composition \% } \\
\hline $\mathrm{SiO}_{2}$ & $\mathrm{Al}_{2} \mathrm{O}_{3}$ & $\mathrm{Fe}_{2} \mathrm{O}_{3}$ & $\mathrm{CaO}$ & $\mathrm{MgO}$ & $\mathrm{Na}_{2} \mathrm{O}$ & $\mathrm{K}_{2} \mathrm{O}$ & $\mathrm{TiO}_{2}$ \\
\hline 62.22 & 11.096 & 4.033 & 3.583 & 0.599 & 0.78 & 3.266 & 0.339 \\
\hline
\end{tabular}

\section{B. Experimental work}

The experiment is divided into two stages. Stage one is the IX process by natural zeolite, and stage two is RO process, as shown in Fig.1. First stage consists of tank for the feed water, feed water pump with speed controller, IX bed (zeolite bed) and IX outlet tank. IX bed has a cylindrical shape with 7 $\mathrm{cm}$ diameter and $25 \mathrm{~cm}$ height. The used feed water pump runs with a small flow rate of $30 \mathrm{ml} / \mathrm{min}$. The IX process performance was evaluated by means of the solution $\mathrm{pH}$ and electrical conductivity measurements.

Synthetic feed water was made by addition of appropriate amount of Sodium Chloride $(\mathrm{NaCl})$ to deionized water. Water from IX process by zeolite bed with different $\mathrm{NaCl}$ concentrations is used as feed water to the RO membrane process, this stage consists of a diaphragm pump (Water world CDP-9000, maximum flow rate of $1.6 \mathrm{Lpm}$, maximum pressure of $80 \mathrm{psig}$, and motor 24VDC/1.2A), adjustable DC power supply, and finally a spiral wound RO membranes with one pressure regulator in the produced line, the system was also completed with pressure indicator (0-140 psig).

Electrical conductivity is measured by electrical conductivity probe (KDS-1038) from ScienceCube. $\mathrm{pH}$ is measured by inoLab $\mathrm{pH} 720$ from WTW GmbH.

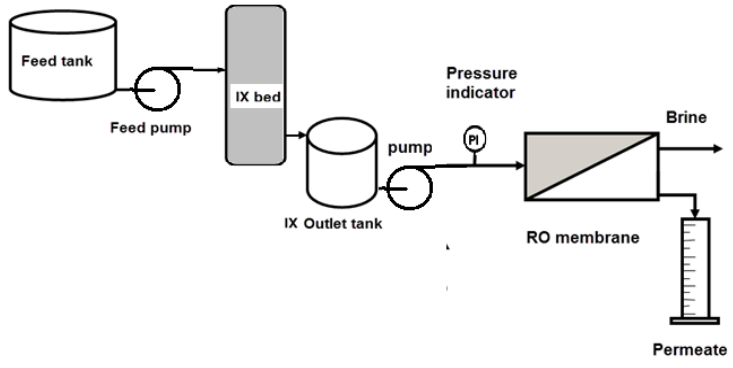

Figure 1. Schematic experimental set-up

By using four samples of feed water with different $\mathrm{NaCl}$ concentrations to the IX process and the produced water is introduced to the two types of RO membranes to be filtrated, the effect of using zeolite bed on the performance of each membrane can be determined. Table 2 illustrates the properties of feed water to RO membranes.

TABLE 2

PROPERTIES OF THE FEED WATER TO RO MEMBRANES

\begin{tabular}{|c|c|c|c|c|}
\hline \multirow[b]{2}{*}{$\begin{array}{l}\text { Feed water } \mathrm{NaCl} \\
\text { concentration } \\
(\mathrm{ppm})\end{array}$} & \multicolumn{2}{|c|}{ Without IX process } & \multicolumn{2}{|c|}{ With IX process } \\
\hline & $\begin{array}{c}\text { Electrical } \\
\text { conductivity } \\
(\mu \mathrm{s} / \mathrm{cm})\end{array}$ & $\mathrm{pH}$ & $\begin{array}{c}\text { Electrical } \\
\text { conductivity } \\
(\mu \mathrm{s} / \mathrm{cm})\end{array}$ & $\mathrm{pH}$ \\
\hline 1050 & 2120 & 8.27 & 1719 & 7.5 \\
\hline 1650 & 3120 & 7.95 & 2320 & 6.72 \\
\hline 2050 & 4040 & 8.2 & 2460 & 6.75 \\
\hline 3150 & 6300 & 7.8 & 4936 & 6.82 \\
\hline
\end{tabular}

\section{Performance of RO membranes}

To evaluate the performance of TFN and TFC membranes, the water recovery $(\operatorname{Re} \%)$, the membrane flux and salt rejection for every feed water concentration are calculated. Salt rejection $(S R \%)$ was evaluated based on the salt concentration difference in the feed and permeate solutions [21] using Eq. (1).

$S R \%=\left(1-\frac{C_{p}}{C_{f}}\right) \times 100$

where $C_{p}$ and $C_{f}$ are the concentrations of salt in permeate and feed solution $(\mathrm{mg} / \mathrm{L})$; respectively.

The volume of permeate was collected at certain time intervals to calculate the water flux of the tested membranes using Eq. (2).

$J=\frac{V}{A t}$

where $J$ is water flux $\left(\mathrm{L} / \mathrm{m}^{2} \mathrm{~h}\right), A$ is effective area of the membrane $\left(\mathrm{m}^{2}\right)$ and $V$ is volume of permeate $(\mathrm{L})$ collected during a time interval $t(\mathrm{~h})$.

The water recovery is calculated from

$\operatorname{Re} \%=\frac{Q_{p}}{Q_{f}} X 100$ 
where $Q_{P}$ and $Q_{f}$ are flow rate of permeate $\left(\mathrm{m}^{3} / \mathrm{h}\right)$ and feed water; respectively.

\section{The specific energy consumption of RO membranes}

Energy is required to overcome the osmotic pressure and produce desalinated water. The energy needed for RO membrane depends on water recovery, membrane permeability, operational flux and feed water salinity [22]. TFN-RO membrane has higher water permeability when compared to TFC-RO membrane which improve the membrane flux and reduce the driving pressure needed. The most important aspect of TFN-RO membranes is the reduction in specific energy consumption (SEC) due to lower feed pressure. SEC can be calculated by Darwish et. al.[23] with the following Eq.s:

$$
\begin{aligned}
& S E C=\frac{E_{H P}}{Q_{p}} \\
& E_{H P}=\frac{Q_{H P} \times P_{H P}}{\eta_{H P}}
\end{aligned}
$$

where $S E C$ measured in $\left(\mathrm{kW} . \mathrm{h} / \mathrm{m}^{3}\right), E_{H P}$ is the power of high pressure pump $(\mathrm{kW}), Q_{p}$ is the permeate water flow rate $\left(\mathrm{m}^{3} / \mathrm{h}\right), Q_{H P}$ is the high pressure pump flow rate $\left(\mathrm{m}^{3} / \mathrm{s}\right), P_{H P}$ is the high pressure pump outlet pressure $(\mathrm{Kpa})$ and $\eta_{H P}$ is high pressure pump efficiency.

\section{E. RO membrane water permeability and salt permeability}

Membrane water permeability and salt permeability were calculated by Tiraferri [24] as follows:

Membrane water permeability

$$
K=\frac{J}{\Delta p}
$$

where $\Delta p$ the driving pressure $(\mathrm{Pa}), K$ is is the water permeability (m/pa.s).

Salt permeability is calculated as follows:

$$
B=\left(\frac{1}{S R}-1\right) . J
$$

where $B$ is the salt permeability $(\mathrm{m} / \mathrm{s})$.

\section{RESULTS AND DISCUSSION}

To evaluate the membrane performance of the two types of RO membranes with the feed water produced from zeolite bed and without using zeolite bed, the membrane flux, membrane salt rejection and water recovery for feed water with different $\mathrm{NaCl}$ concentrations are calculated.

\section{A. RO membrane flux}

From experimental results, we can see that at the same pressure and lab temperature, TFN membrane has a higher flux than the TFC membrane for the all samples of water which were produced from IX process. Fig. 2 illustrates that the flux of TFN is 1.5 times that of TFC for water with 1650 ppm $\mathrm{NaCl}$ concentration. That is due to presence of nanoparticles in polyamide layer of TFN membrane which increases membrane permeability by providing nanochannels which enable water passage and prevent salt ions.
By using different $\mathrm{NaCl}$ concentrations for feed water and without using zeolite bed, the experiments investigated that the flux for TFN membrane is better than that for TFC membrane. Fig. 3 ilustrates that the flux for TFN membrane is 1.54 time that for TFC membrane at $\mathrm{NaCl}$ concentrations of $1650 \mathrm{ppm}$.

The results indicate that using zeolite bed before RO membrane will enhance its performance by increasing the membrane flux, that is because using zeolite bed decreases the water osmotic pressure by adsorption of Sodium ions. Also, the incorporation of zeolite nanoparticles into the polyamide layer of TFC-RO membrane producing TFN-RO membrane provide channels that can filter salty water at a rate faster than conventional $\mathrm{RO}$ membranes and improving the membrane water permeability by rejecting dissolved ions while enabling water molecules to pass

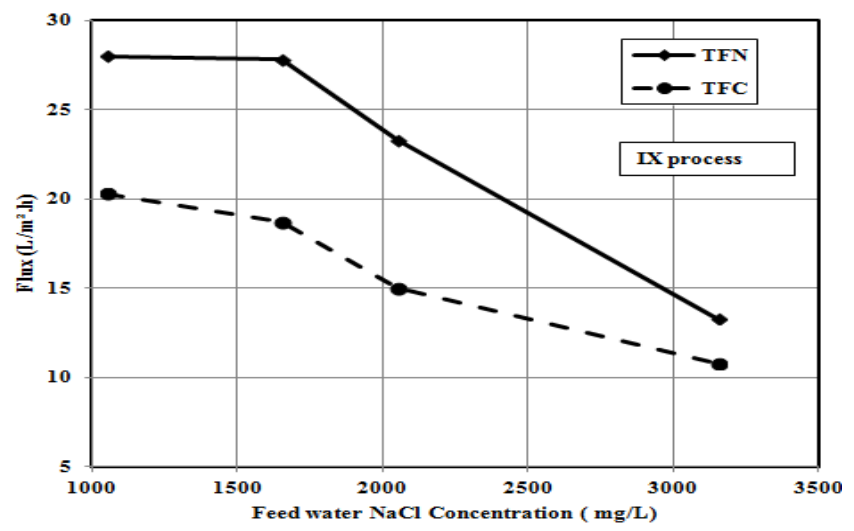

Figure 2. Flux of TFC and TFN membranes at different feed water $\mathrm{NaCl}$ concentrations with IX process.

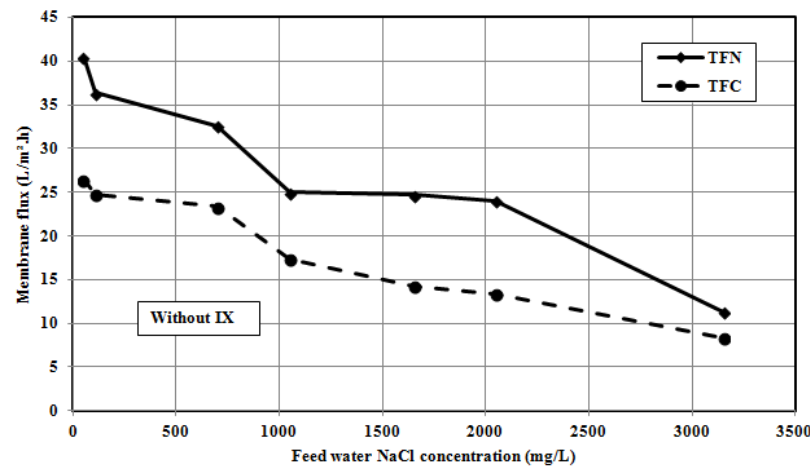

Figure 3. TFN and TFC membranes flux at different feed water $\mathrm{NaCl}$ concentrations without IX proces

\section{B. RO membrane salt rejection}

From Figs. 4 and 5 we can see that the salt rejection for TFN membrane is very close to that of TFC membrane for the four water samples. We can conclude that incorporating nanoparticles into the PA layer of the membrane has nearly no effect on the membrane salt rejection. Also the salt rejection decreases by increasing the feed water concentration that is due to increase of the osmotic pressure of feed water which needs increasing in the driving pressure to overcome it. 


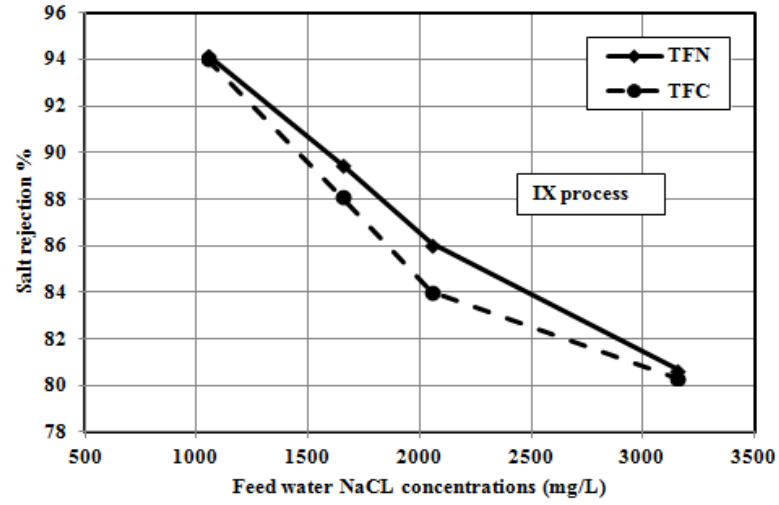

Figure 4. Salt rejection of TFC and TFN membranes at different feed water salt concentrations with IX process.

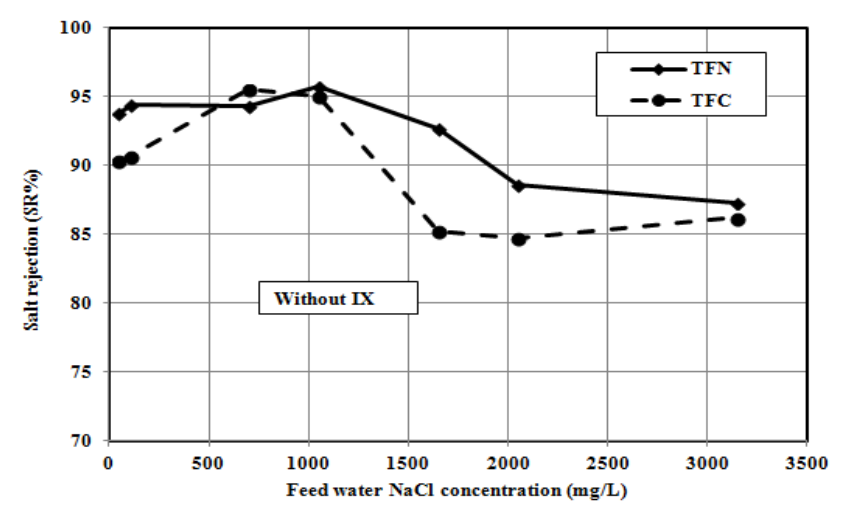

Figure 5. Salt rejections for TFN and TFC RO membranes at different feed water $\mathrm{NaCl}$ concentrations without IX process.

\section{RO membrane recovery}

From Figs. 6 and 7 we can see that TFN membrane recovery is $37.5 \%$ more than that of TFC membrane with feed water $\mathrm{NaCl}$ concentration of $2050 \mathrm{ppm}$ and TFC membrane recovery increased by $18.3 \%$ using IX produced water with the same initial concentration. That is due to improving of membrane hydrophilicity and water permeability which will increase the permeate flow rate and as a result decreases the brine flow rate.

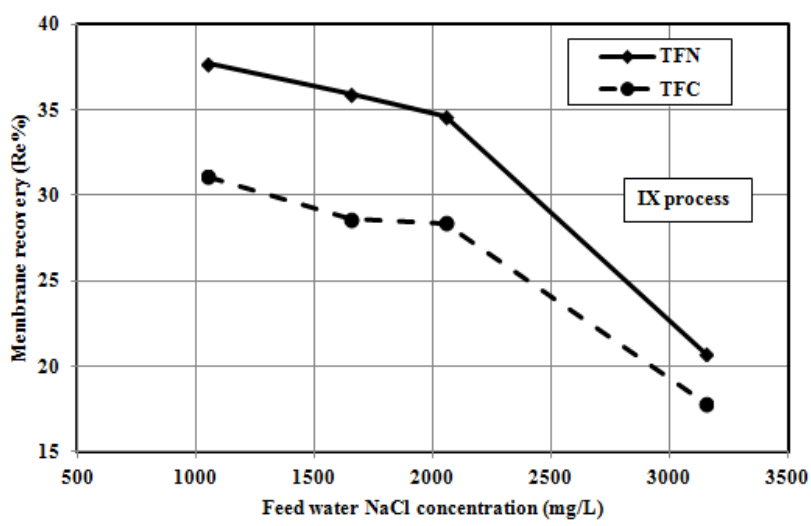

Figure 6. Recovery of TFC and TFN membranes at different feed water $\mathrm{NaCl}$ concentrations with IX process.

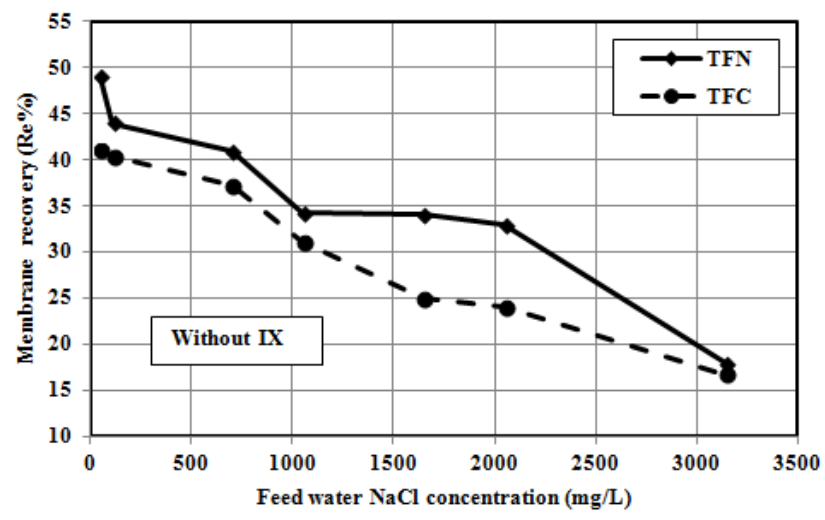

Figure 7. Rrecovery for TFN and TFC membrane at different feed water $\mathrm{NaCl}$ concentrations without IX process

\section{RO membrane water permeability and salt} permeability

By using IX produced water, Fig. 8 illustrates that increasing of salt concentration in feed water decreases the membrane permeability because of increasing salt concentration will increase the osmotic pressure so the effective driving force for water flow declines and the flow rate drops. Without IX process and from Fig.9 we can see that feed water concentration has the same effect on membranes water permeability but using IX process enhances TFC membrane water permeability not as TFN one, also from Eq. (6) we can see that water permeability depends on membrane flux which increases by using TFN membrane and increases water permeability. TFN membrane permeability increases with $56 \%$ than that of TFC membrane permeability at $2050 \mathrm{mg} / \mathrm{L}$ water concentration with IX process.

From Fig. 10 and Fig. 11, we notice that salt permeability increases with small values by using TFN membrane. As the $S R \%$ decreases by increasing water $\mathrm{NaCl}$ concentration and from $\mathrm{Eq}$ (7) we can see that salt permeability depends on water flux and salt rejection and water flux also decreases so we can say that the salt permeability increases with $S R \%$ decreasing. That is due to membrane structure with thin film nanocomposite materials which make ions passage more easily than in TFC membrane.

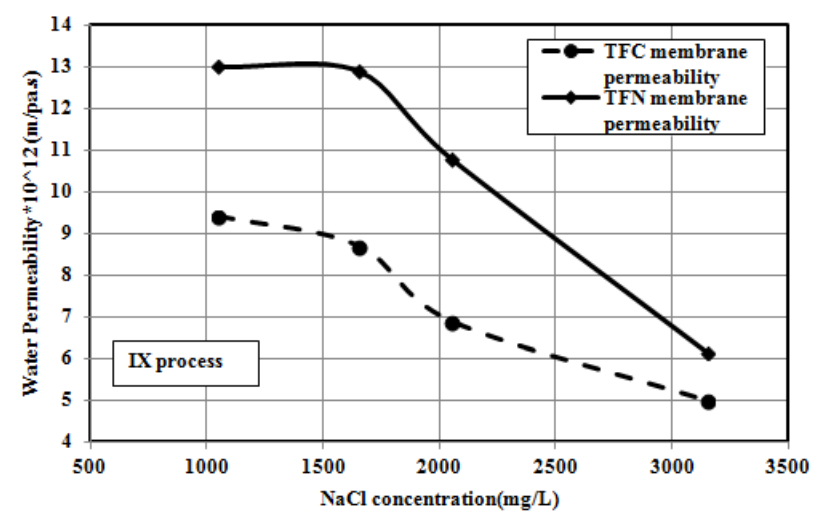

Figure 8 . Effect of feed water $\mathrm{NaCl}$ concentration on membrane permeability with IX process 


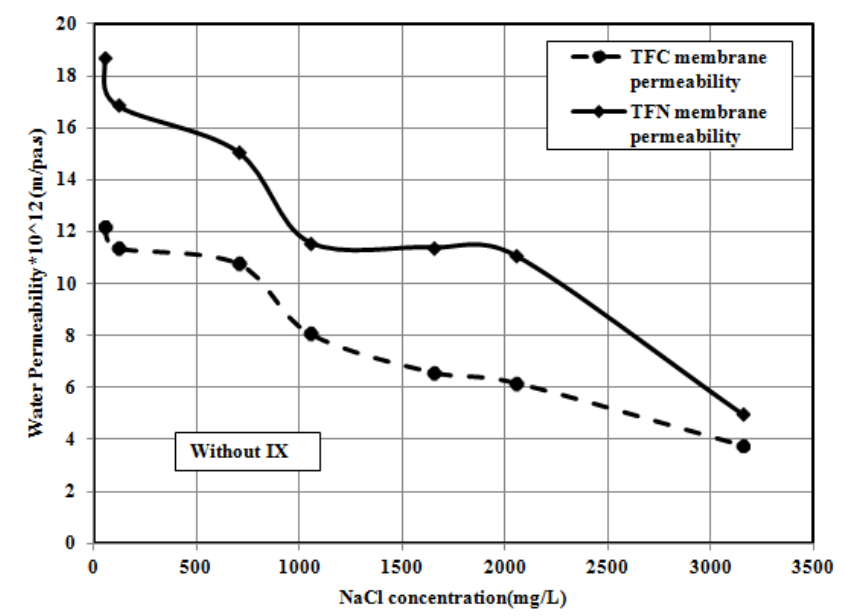

Figure 9. Effect of feed water $\mathrm{NaCl}$ concentration on membrane permeability without IX process

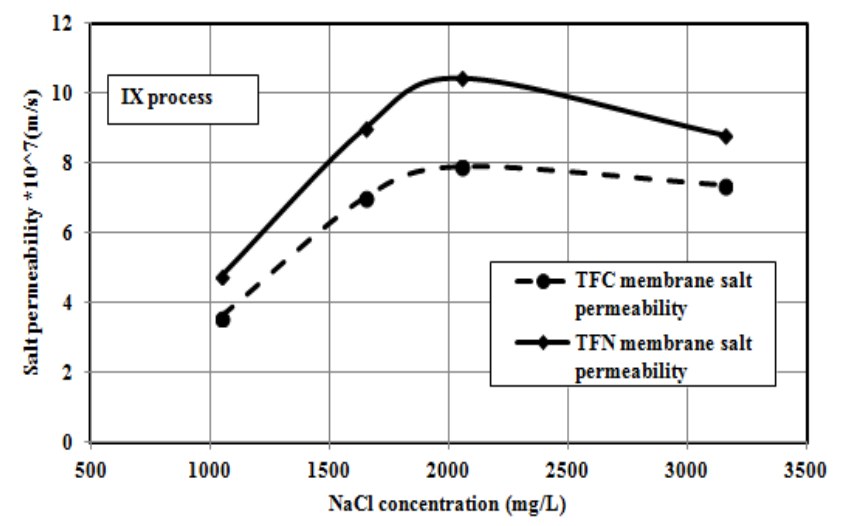

Figure 10. Effect of feed water $\mathrm{NaCl}$ concentration on membrane salt permeability with IX process

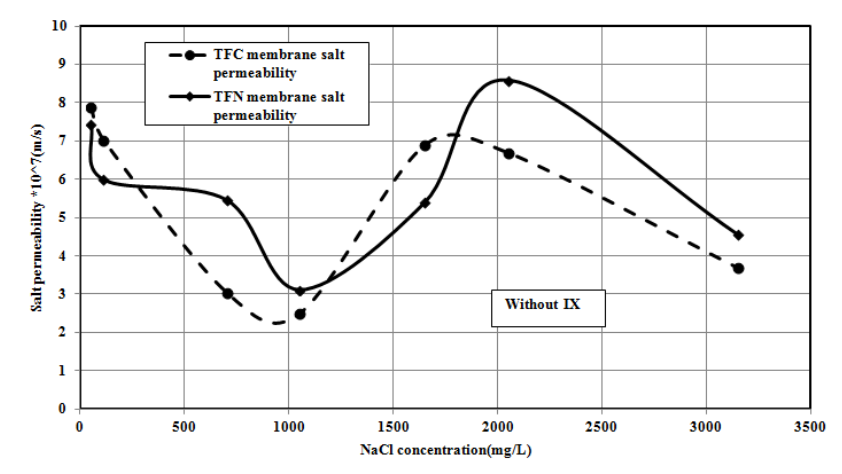

Figure 11. Effect of feed water $\mathrm{NaCl}$ concentration on salt permeability without IX process

\section{E. Specific energy consumption of TFC and TFN-RO membranes}

Reducing feed pressure requirement during desalination is a key to reduce energy consumption. The feed water to the RO process is pressurized using feed pump to supply the necessary pressure to force water through the membrane to exceed the osmotic pressure and overcome differential pressure losses through the system. By using Eq (4), Fig. 12 illustrates that SEC for TFC membrane is $23 \%$ higher than that for TFN membrane with 2050 ppm feed water $\mathrm{NaCl}$ concentration. That is due to lower feed pressure required by TFN- RO for the same inlet water concentration. Also, permeate water flow rate increases by using TFN membrane which decreases SEC.

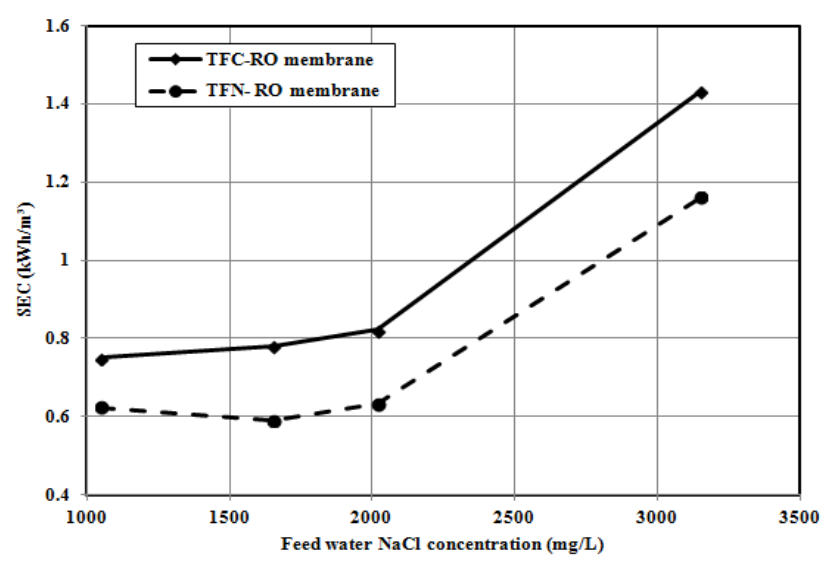

Figure 12. Specific energy consumption for TFN and TFC- RO membranes

\section{CONCLUSION}

Using thin film nanocomposite (TFN)-RO membrane prepared by incorporating of nanoparticles into the polyamide layer of TFC membrane to filtrate water from IX process by zeolite bed and water without IX process is designed and investigated experimentally. From the results it could be concluded the following proof of concepts:

- Using IX bed increases TFC membrane flux by $12.8 \%$ for feed water with $2050 \mathrm{ppm}$ sodium chloride conccentration.

- $\quad$ The permeate flux was enhanced by $55.5 \%(23.3$ $\mathrm{L} / \mathrm{m}^{2} . \mathrm{h}$ ) for water with $2050 \mathrm{ppm}$ sodium chloride conccentration with little increase in the salt rejection using TFN membrane.

- However, using TFN membrane increases the membrane flux, it has a little increase in the salt rejection.

- The increasing of the membrane flux by using TFN membrane will reduce the cost of the filtrated water and decreases brine water disposal costs.

- There is $23 \%$ reduction in specific energy consumption by using TFN - RO membrane for water with 2050 ppm $\mathrm{NaCl}$ concentration.

\section{ACKNOWLEDGMENT}

Corresponding author is thankful to faculty of engineeringKafrelsheikh University for lab measurements. Also, she wants to thank her supervisors for thier valuable suggestions and help

\section{REFERENCES}

[1] Nidal Hilal, Victor Kochkodan, Hasan Al Abdulgader, Daniel Johnson, "A combined Ion Exchange-Nanofiltration Process for Water Desalination: II. Membrane selection,” Desalination, Vol. 363, pp. 5157, 2015

[2] Hasan Al Abdulgader, Victor Kochkodan, Nidal Hilal, "Hybrid Ion Exchange - Pressure Driven Membrane Processes in Water Treatment: A review," Separation and Purification Technolog, Vol. 116, pp. 253 264, 2013 
[3] A. Perez Gonzalez, R. Ibanez, P. Gomez, A.M. Urtiaga, I. Ortiz, J.A. Irabien, "Recovery of Desalination Brines: Separation of Calcium Magnesium and Sulfate as A pre-treatment Step," Desalination and Water Treatment, Vol. 56(13), pp. 1-9, 2014

[4] Anand Venkatesan and Phillip C. Wankat, "Simulation of Ion Exchange Water Softening Pretreatment for Reverse Osmosis Desalination of Brackish Water," Desalination, Vol.271, pp. 122-131, 2011

[5] A.E. Ghaly and M. Verma, "Desalination of Saline Sludges Using IonExchange Column with Zeolite," American Journal of Environmental Sciences, Vol. 4 (4), pp. 388-396, 2008

[6] F. Shokrian, K. Solaimani, GH. Nematzadeh, P. Biparva, "Removal of $\mathrm{NaCl}$ from Aqueous Solutions by Using Clinoptilolite," IJFAS Journal, Vol. 4(1), pp. 50-54, 2015

[7] Edy Wibowo, Sutisna, Mamat Rokhmat, Riri Murniati, Khairurrijal, Mikrajuddin Abdullah,"Utilization of Natural Zeolite as Sorbent Material for Seawater Desalination," Procedia Engineering, Vol. 170, pp. $8-13,2017$

[8] Hanaa M. Hegab, Yasodinee, Milena Ginic-Markovic, Linda Zou, "Improving the fouling resistance of brackish water membranes via surface modification with graphene oxide functionalized chitosan,' Desalination, Vol. 365, pp.99-107, 2015

[9] Mary Laura Lind, Byeong.H Jeong, Arun Subramani, Xiaofie Huang and Eric Hoek, "Effect of mobile cation on zeolite- polyamide thin film nanocomposite membranes,” J. Mater. Res, Vol. 5, pp. 1624-1631, 2009

[10] Eun-Sik Kim, Geelsu Hwang, Mohamed Gamal El-Din and Yang Liu, "Development of nanosilver and multiwalled carbon nanotubes thinfilm nanocomposite membrane for enhanced water treatment,'Journal of Membrane Science, Vol. 394, pp.37-48, 2012

[11] Sang Gon Kim, Jeong Hwan Chun, Byung-Hee Chun and Sung Hyun Kim, "Preparation, characterization and performance of poly (aylene ether sulfone)/modified silica nanocomposite reverse osmosis membrane for seawater desalination," Desalination, Vol. 325, pp. 7683, 2013

[12] Haiyang Zhao, Shi Qiu, Liguang Wu, Lin Zhang, Huanlin Chen, Congjie Gao, "Improving the performance of polyamide reverse osmosis membrane by incorporation of modified multi-walled carbon nanotubes," Journal of Membrane Science, Vol. 450, pp. 249-256, 2014

[13] D Emadzadeh, W.J.Lau, M Rahbari-Sisakht, A Daneshfar, M Ghanbari, A Mayahi, T Matsuura, AF Ismail, "A novel thin film nanocomposite reverse osmosis membrane with superior anti-organic fouling affinity for water desalination," Desalination, Vol. 368, pp. 106-113, 2015

[14] Mahdi Fathizadeh, Abdolreza Aroujalian, Ahmadreza Raisi, "Effect of added $\mathrm{NaX}$ nano-zeolite into polyamide as a top thin layer of membrane on water flux and salt rejection in a reverse osmosis process," J. Membrane Science, Vol. 375, pp. 88-95, 2011

[15] Byeong-Heong Jeong, Eric MV Hoek, Yushan Yan, Arun Subramani, Huang, Xiaofei Gil Hurwitz, AsimK Ghosh, Anna Jawor, "Interfacial polymerization of thin film nanocomposites: a new concept for reverse osmosis membranes," Journal of Membrane Science, Vol. 294, pp. 1-7, 2007

[16] WJ Lau, Stephen Gray, T Matsuura, D Emadzadeh, J Paul Chen, AF Ismail, "A review on polyamide thin film nanocomposite (TFN) membranes: History, applications, challenges and approaches," Water Research, Vol. 80, pp. 306-324, 2015

[17] E R Nightingale Jr, "Phenomenological Theory of Ion Solvation Effective Radii of Hydrated Ions,'J. Phys. Chem, Vol. 63(9), pp. 1381-1387, 1959

[18] M Ghanbari, D Emadzadeh, WJ Lau, T Matsuura, M Davoody, AF Ismail, "Super hydrophilic $\mathrm{TiO}_{2} / \mathrm{HNT}$ nanocomposites as a new approach for fabrication of high performance thin film nanocomposite membranes for FO application," Desalination, Vol. 371 , pp. 104-114, 2015

[19] AK Ghosh, RC Bindal, S Prabhakar, PK Tewari, "Composite Polyamide Reverse Osmosis (RO) Membranes - Recent Developments and Future Directions," technology development article, Vol. 321, pp. 43-51, 2011

[20] Pinar Cay-Durgun, Cailen McCloskey, John Konecny, Afsaneh Khosravi, Mary Laura Lind, "Evaluation of thin film nanocomposite reverse osmosis membranes for long-term brackish water desalination performance," Desalination, Vol. 404, pp.304-312, 2017

[21] R.W. Baker, Membrane Technology and Applications, 2nd ed., John Wiley, New York, 2004

[22] A Subramani, M Badruzzaman, J Oppenheimer, JG Jacangelo, "Energy minimization strategies and renewable energy utilization for desalination: a review," Water Res, Vol. 45, pp. 1907-1920, 2011
[23] Darwish, M, Asfour, N and Al-Najem, "Energy Consumption in equivalent work by different desalinating methods: case study for Kuwait," Desalination, vol. 152, pp. 83-92, 2002

[24] Tiraferri, Ngai Yin Yip, William A. Phillip, Jessica D. Schiffman, Menachem Elimelech, Relating performance of thin-film composite forward osmosis membranes to support layer formation and structure, Journal of Membrane Science, Vol.367, pp.340-352, 2011 